\title{
Analisis Pola Hubungan Antara Konsumsi Listrik Dengan Temperatur dan Fitur Geografi Menggunakan Association Rule Mining
}

\author{
Haris Prasetyo, Imam Mukhlash, dan Nurul Hidayat \\ Departemen Matematika, Fakultas Matematika Komputasi dan Sains Data, Institut Teknologi Sepuluh Nopember \\ (ITS) \\ email:imamm@matematika.its.ac.id
}

\begin{abstract}
Abstrak-Perkembangan zaman semakin mempengaruhi pola hidup masyarakat yang mana menyebabkan penggunaan listrik mengalami peningkatan. Sementara itu biaya pengadaan tenaga listrik serta distribusinya juga membutuhkan biaya yang tidak kecil. Maka dari itu diperlukan kajian lebih lanjut tentang pengetahuan profilprofil penggunaan listrik tiap wilayah agar pendistribusiannya efektif. Untuk menggali pengetahuan ini diperlukan teknik data mining. Dalam penelitian ini digunakan algoritma fp-growth yaitu dengan membuat $f p$ tree, conditional pattern base lalu menemukan pattern atau pola yang terbentuk dan diubah menjadi suatu rule. Dari data selama satu tahun (September 2015-Agustus 2016) daerah Sidoarjo, didapat bahwa wilayah yang jauh dengan area perikanan cenderung tinggi dalam penggunaan listriknya. Pemakaian listrik juga tinggi untuk daerah yang dekat dengan pertanian dan jalan besar. Lalu ketika temperatur berkis ar $28,5^{\circ}-29,5^{\circ}$ pemakaian listrik tergolong rendah
\end{abstract}

Kata Kunci-Konsumsi Listrik, Data Mining, Asosiasi, FPGrowth.

\section{PENDAHULUAN}

$\mathrm{K}$ EBERLANJUTAN energi selalu menjadi topik perbincangan yang menarik untuk terus dikaji. Salah satunya yaitu energi listrik. Saat ini banyak tersebar sloganslogan seperti 'save energy' dan lain sebagainya. Hal ini menandakan bahwa kesadaran masyarakat akan keberlanjutan energi semakin meningkat. Hal ini dipengaruhi oleh perkembangan zaman yang semakin maju yang menyebabkan teknologi-teknologi yang digunakan manusia juga semakin canggih. Namun sebagian besar teknologi tersebut membutuhkan energi listrik untuk penggunaannya yang akhirnya akan berdampak pada peningkatan penggunaan energi listrik. Sementara itu sebagian besar bauran energi mix untuk pengadaan tenaga listrik bergantung pada sumber daya yang relatif lama atau tidak bisa diperbarui. Di sisi lain biaya pengadaan serta distribusinya juga membutuhkan biaya yang tidak kecil. Maka dari itu diperlukan kajian lebih lanjut tentang pengetahuan profil-profil penggunaan listrik tiap wilayah agar pendistribusiannya efektif. Untuk menggali pengetahuan ini diperlukan teknik data mining. Pengetahuan yang diperoleh berupa suatu rule yang berkaitan dengan penggunaan listrik. Informasi seperti itu bisa menjadi bahan pertimbangan dalam menentukan distribusi energi listrik agar lebih efektif.

Dalam penelitian ini, algoritma yang digunakan yaitu fpgrowth, salah satu algoritma asosiasi yang digunakan untuk menemukan pola hubungan antar dua hal atau lebih. Algoritma ini merupakan pengembangan dari metode asosiasi yang sebelumnya yang dikenal dengan algoritma apriori. Berbeda dengan algoritma apriori yang butuh berkali-kali untuk memindai data dari basis data, fp-growth butuh dua kali pemindaian data. Langkah selanjutnya yaitu membentuk $f p$ tree sebagai pengganti basis data yang akan dipindai untuk yang kesekian kalinya jika pada algoritma apriori. Langkah selanjutnya dibentuklah conditional pattern base, lalu menemukan frequent pattern atau pola yang sering muncul. Dan diakhiri dengan generate rule. Rule ini merupakan kombinasi dari beberapa item yang sesuai dengan frequent pattern tersebut.

Data yang digunakan adalah data salah satu kota di jawa timur yaitu kabupaten Sidoarjo. Data tersebut antara lain temperatur rata-rata per hari, data jarak setiap wilayah dengan fitur geografi (kawasan pertanian, perikanan, dan jalan besar), serta data penggunaan listrik per bulan dari masing-masing wilayah tersebut. Data temperatur nantinya akan diubah menjadi data bulanan dengan menggunakan salah satu rumus agregasi yaitu average. Data jarak setiap wilayah dengan fitur geografi didapat dari pengukuran peta menggunakan software GIS.

\section{TINJAUAN PUSTAKA}

\section{A. Penelitian Terkait}

Penulis memulai penelitian ini dengan terlebih dahulu melakukan studi kepustakaan dari penelitian-penelitian dan sumber-sumber lain. Penelitian tersebut membahas tentang topik yang terkait dengan penelitian penulis, antara lain mengenai masalah yang diangkat serta mengenai metode yang digunakan penulis.

Dengan menggunakan sebuah formula yang disebut ideal curve Jovanovic, S dkk [1] melakukan sebuah penelitian tentang akibat atau dampak dari suatu perubahan temperatur udara per hari terhadap konsumsi listrik pada kota Kragujevac (Serbia). Dalam penelitian tersebut dinyatakan bahwa 
temperatur rata-rata udara tiap hari merupakan sebuah parameter iklim yang paling berpengaruh dan memberikan dampak yang luas. Peningkatan dan penurunan konsumsinya tergantung pada simpangan dari temperatur rata-rata per hari. Pada musim dingin terjadi peningkatan konsumsi listrik sebagai hasil dari proses pemanasan baik di daerah pemukiman maupun perkantoran. Selama musim panas yang panjang dan ekstrem juga terdapat suatu kecenderungan peningkatan konsumsi lis trik karena pendingin udara.

Telah dilakukan sebuah penelitian konsumsi listrik per jam terhadap pemukiman Norwegia [2]. Pada penelitian tersebut dilakukan analisa untuk mengetahui seberapa besar sistem pemanasan mempengaruhi konsumsi listrik per jam oleh setiap rumah. Data meteran listrik per jam, data cuaca, dan data respon dari survei rumah tangga digunakan, serta model multi regresi diaplikasikan untuk mengetahui dampak dari sistem pemanas ini.

Penelitian lain dilakukan di Indonesia untuk mengetahui karakteristik konsumsi listrik rumah tangga. Faktor yang menggiring konsumsi listrik tersebut ditentukan melalui survei lapangan dan diklasifikasikan menurut bagaimana penggunaannya. Hubungan antara konsumsi listrik dengan faktor yang mempengaruhi tersebut dievaluasi menggunakan analisa data multivariat. Penelitian tersebut dilakukan di dua kota berbeda untuk memperoleh perbandingan. Dan dari hasil yang diperoleh, disimpulkan bahwa kebijakan konservasi energi tidak bisa diperlakukan secara general melainkan harus lebih spesifik berdasarkan karakteristik yang diadopsi oleh masing-masing daerah [3].

Rathod dan Garg melakukan sebuah penelitian tentang hubungan antara konsumsi listrik dengan temperatur dan fitur geografi [4]. Penelitian ini mengambil data dari kota Shangli, India. Dalam penelitian ini mereka menggunakan algoritma apriori dan fitur geografi yang dipakai adalah sungai, sawah, lahan terbuka, dan jalan tol. Pada penelitian [1] dan [2] hanya dilakukan penelitian terkait temperatur. Sedangkan di penelitian [4], cakupannya sudah lebih luas yaitu menambah keterkaitannya dengan fitur geografi. Namun, algoritma yang digunakan yaitu apriori masih memiliki banyak kekurangan dan keterbatasan.

\section{B. Data Mining}

Aplikasi basis data sudah banyak diterapkan di berbagai bidang seperti manajemen industri, ilmu pengetahuan, administrasi pemerintah, dan masih banyak bidang yang lainnya. Hal ini menyebabkan data yang dihasilkan dari bidang-bidang tersebut sangat besar dan berkembang pesat. Dari keadaan seperti itu, muncul kebutuhan yaitu teknik seperti apa yang bisa digunakan untuk mengolah data tersebut sehingga bisa diperoleh informasi implisit yang berharga dari data-data tersebut. Data Mining adalah suatu istilah yang digunakan untuk menguraikan penemuan pengetahuan di dalam data. Data Mining adalah proses yang menggunakan teknik statistik, matematika, kecerdas an buatan, machine learning untuk mengekstraksi dan informasi yang bermanfaat dan pengetahuan yang terkait dari berbagai data besar [5].

\section{Association Rule Mining}

Association rule mining adalah pencarian aturan-aturan hubungan antar item dari suatu basis data transaksi atau basis data relasional. Dengan kata lain menemukan frequent patterns, asosiasi, korelasi, atau causal structures diantara himpunan item atau obyek dalam database transaksional, database relasional, dan penyimpanan lainnya.

Misal I adalah suatu himpunan set, maka suatu rule didefinisikan dengan $\mathrm{A} \Rightarrow \mathrm{B}$ dimana $\mathrm{A} \subset \mathrm{I}, \mathrm{B} \subset \mathrm{I}, \mathrm{A} \cap \mathrm{B}=\varnothing$. Dua parameter yang digunakan untuk mendapatkan rule yaitu:

1. Support (s), menyatakan probabilitas item-itemnya muncul dalam basis data atau bisa dikatakan suatu transaksi memuat $\{\mathrm{A} \cup \mathrm{B}\} . \mathrm{S}=\operatorname{support}\left(\left\{\mathrm{A} \cup_{\mathrm{B}}\right\}\right)$

2. Confidence (c), menyatakan probabilitas bahwa jika itemitem pada ruas kiri muncul maka item-item pada ruas kanan juga akan muncul atau bisa dikatakan probabilitas bersyarat. $\mathrm{C}=$ support $(\{\mathrm{A} \cup \mathrm{B}\}) / \operatorname{support}(\{\mathrm{A}\})$.

3. Lift, nilai lift menunjukkan hubungan antar item. Lift bernilai $<1$ menujukkan bahwa item-item tersebut berkorelasi negatif, dengan kata lain kemunculan salah satu item mempengaruhi hal yang sebaliknya pada kemunculan item lainnya. Untuk nilai =1 menandakan bahwa hubungan itemitem adalah independent. Dan untuk nilai $>1$ menunjukkan bahwa item-item tersebut berkorelasi positif. Nilai lift bis a dicari dengan cara membagi confidence dengan expected confidence. Sedangkan expected confidence didapat dari support $(\{\mathrm{Y}\}) /$ jumlah record.

$$
\begin{aligned}
\text { lift } & =\frac{\text { confidence }}{\text { expected confidence }} \\
\text { conf } & =\frac{\text { support } A \cup B}{\text { support } A} \\
\text { expt conf } & =\frac{\text { support } B}{\text { jumlah record }}
\end{aligned}
$$

Salah satu algoritma dari association rule adalah FPGrowth. FP-Growth adalah perbaikan dari algoritma apriori, dibentuk untuk mengatasi kesulitan-kesulitan saat menggunakan apriori. FP-Growth menyederhanakan masalahmasalah yang ada ke dalam bentuk FP-Tree. Dalam FP-Tree ini, setiap node merepresentasikan sebuah item serta jumlahnya, dan setiap cabang merepresentasikan asosiasi yang berbedabeda.

Dengan input berupa suatu record data dari basis data yang mengandung satu atau beberapa item. Dan outputnya adalah frequent pattern, yaitu suatu himpunan yang memuat satu atau lebih item dengan nilai support yang memenuhi besar minimum support yang ditentukan di awal.

Algoritma FP-Growth:

1. Meminindai data dan mencari nilai support dari masingmasing item. Dari semua data yang ada dalam basis datae 


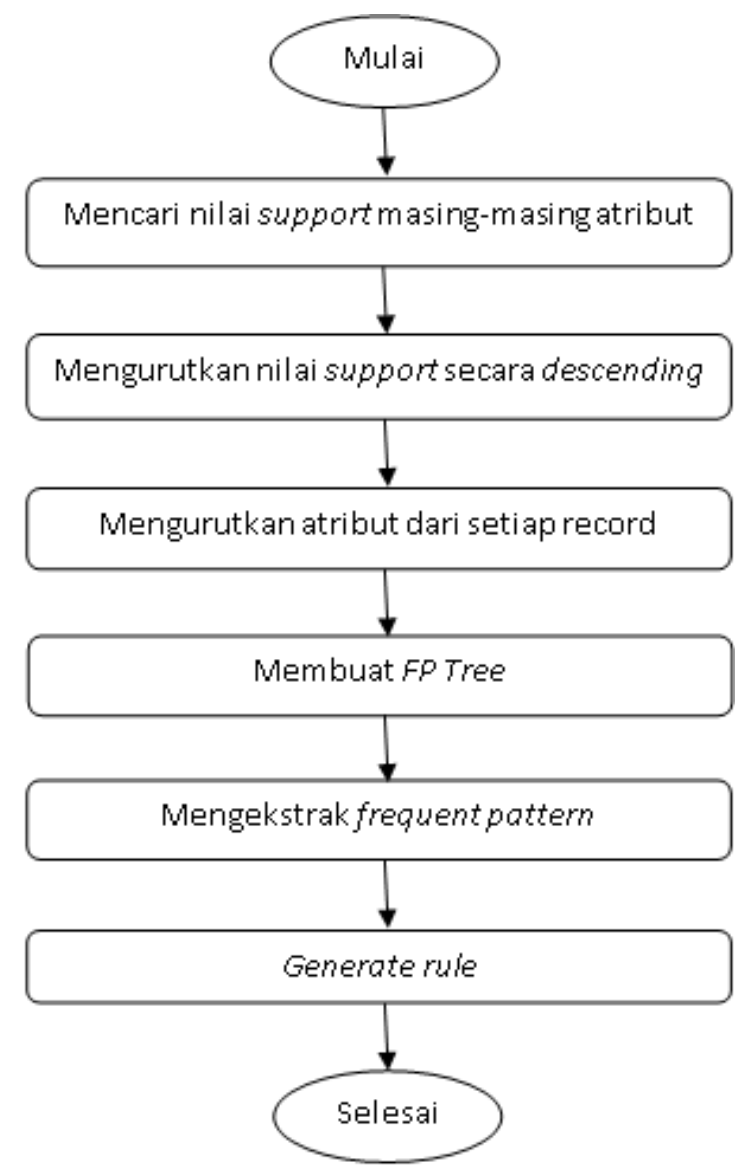

Gambar 1. Alur berjalannya system.

akan dilakukan pemindaian untuk mengetahui frekuensi kemunculan dari masing-masing item tersebut.

2. Urutkan masing-masing support dari terbanyak ke terendah. Setelah mengetahui frekuensi kemunculan atau nilai support, maka akan diurutkan dari yang tertinggi ke terendah.

3. Membuat FP-Tree dari masing-masing transaksi. Akan dibentuk sebuah tree dengan cara menjadikan item dengan nilai support tertinggi sebagai akar (root) dan item dengan nilai support terendah sebagai daun (leaf).

4. Ekstrak frequent itemset, dari bawah ke atas (dari daun ke akar). Dari tree yang sudah terbentuk akan dilakukan ekstrak frequent itemset dimulai dari daun ke akar.

Keuntungan FP-Growth diantaranya bisa meminimalisir pemindaian basis data, menyingkat dataset, tidak perlu candidate generation, dan lebih cepat dibandingkan dengan apriori.

\section{METODOLOGI PENELITIAN}

\section{A. Implementasi Data}

Data yang akan digunakan dalam sistem ini ada 3 macam, yaitu: data penggunaan listrik, data temperatur, dan data jarak antara fitur geografi dengan masing-masing wilayah.

1. Data penggunaan listrik

Data penggunaan listrik yang diperoleh dari data Kabupaten Sidoarjo meliputi jumlah pemakaian (kwh) dan jumlah pelanggan yang terbagi ke dalam 3 rayon, yaitu : sidoarjo kota,

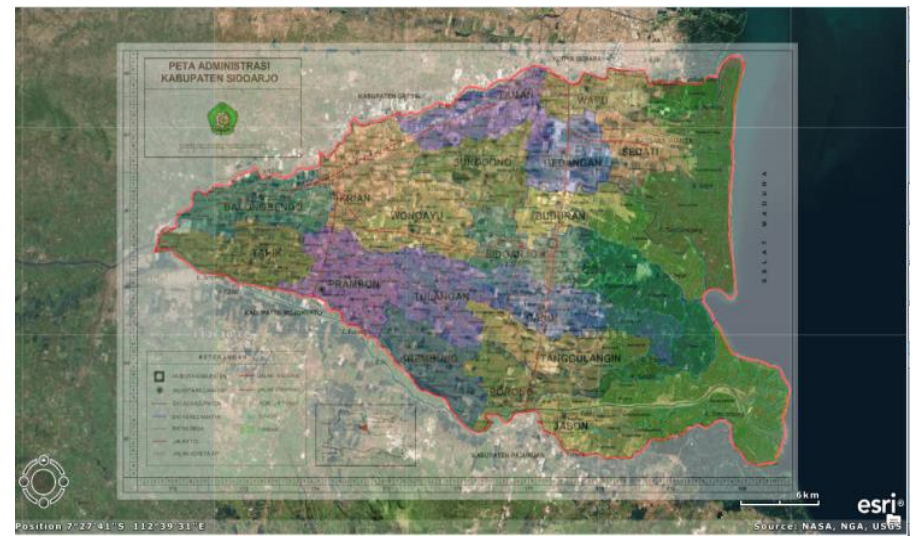

Gambar 2. Membatasi wilayah sidoarjo sesuai peta administrasi yang tersedia.

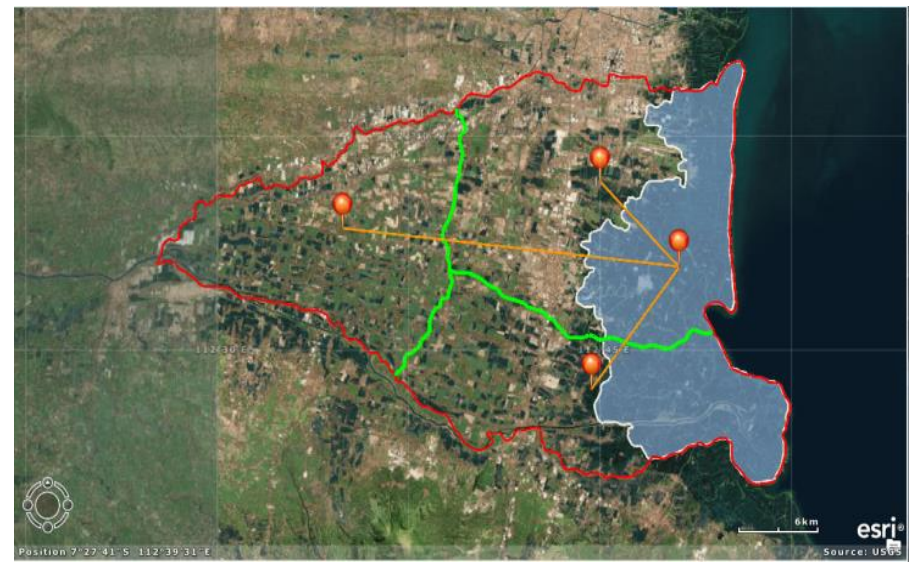

Gambar 3. Mengukur jarak masing-masing rayon ke daerah perikanan.

krian, dan porong. Sebelum data ini diolah ke dalam sistem, perlu dilakukan proses untuk memperoleh bentuk data yang sesuai dengan rancangan sistem yang akan dibuat.

Pengolahan awal data untuk mendapatkan bentuk yang sesuai dengan kebutuhan, akan dikenakan fungsi average atau rata-rata untuk pemakaian masing-masing pelanggan per bulannnya di setiap rayon.

$$
\text { Ave }(\mu)=\frac{\text { pemakaian }}{\text { jumlah pelanggan }}
$$

Setelah diperoleh pemakaian rata-rata untuk masing-masing rayon selama 12 bulan maka akan dibagi menjadi 2 kategori, yaitu rendah $(\leq$ med) dan tinggi $(>$ med $)$.

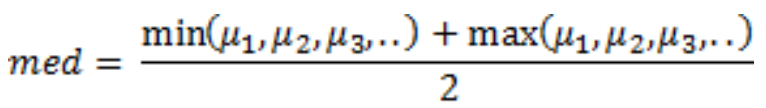

2. Data temperatur

Data temperatur yang diperoleh untuk Kabupaten Sidoarjo meliputi nama stasiun, tanggal, dan suhu rata-rata. Karena stasiun yang tersedia hanya satu maka atribut tersebut diberlakukan untuk seluruh rayon.

Merujuk pada tujuan penelitian ini, yaitu mengetahui pola hubungan antara penggunaan listrik dengan temperatur maka data temperatur yang akan diproses juga harus menyesuaikan dengan data penggunaan listrik. Dikarenakan data penggunaan listrik tersedia untuk per bulan, maka data temperatur juga harus diubah menjadi data bulanan. 


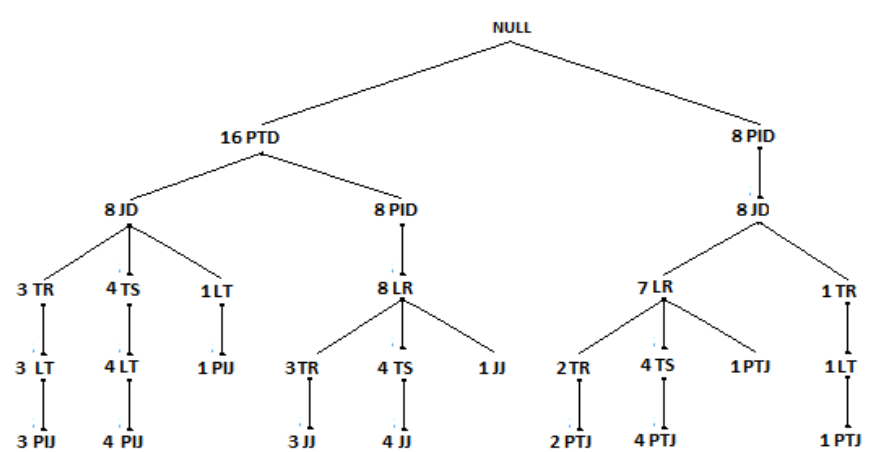

Gambar 4. Gambar fp tree dari data record yang sudah terurut.

Tabel 1.

Data Record

\begin{tabular}{|c|c|c|c|}
\hline No. & Record & No. & Record \\
\hline 1 & TR PTD PU JD LT & 13 & TS PTJ PID JD LR \\
\hline 2 & TR PTD PID JJ LR. & 14 & TS PTD PID JJ LR. \\
\hline 3 & TR PTJ PID JD LR. & 15 & TS PTD PI JD LT \\
\hline 4 & TS PTD PI JD LT & 16 & TR PTD PID JJ LR \\
\hline 5 & TS PTD PID JJ LR. & 17 & TR PTJ PID JD LT \\
\hline 6 & TS PTJ PID JD LR. & 18 & TR PTD PI JD LT \\
\hline 7 & TT PTD PID JJ LR & 19 & TS PTJ PID JD LR. \\
\hline 8 & TT PTJ PID JDLR & 20 & TS PTD PU JD LT \\
\hline 9 & TT PTD PI JDLT & 21 & TS PTD PID JJ LR \\
\hline 10 & TR PTJ PID JD LR. & 22 & TS PTD PU JD LT \\
\hline 11 & TR PTD PID JJ LR. & 23 & TS PTD PID JJ LR \\
\hline 12 & TR PTD PU JD LT & 24 & TS PTJ PID JD LR. \\
\hline
\end{tabular}

Keterangan :

1. Temperatur rendah (TR)

7. Perikanan dekat (PID)

2. Temperatur sedang (TS)

8. Jalan jauh (JJ)

3. Temperatur tinggi (TT)

9. Jalan dekat (JD)

4. Pertanian jauh (PTJ)

10. Listrik rendah (LR)

5. Pertanian dekat (PTD)

6. Perikanan jauh (PIJ)
Tabel 2.

Daftar frequent pattern

\begin{tabular}{|c|c|}
\hline Item & Frequent pattern generated \\
\hline PI & $\begin{array}{l}(\text { PTD, PI : 8), (JD, PI : 8), (LT, PI : 8), (PTD, } \\
\text { JD, PI : 8), (PTD, LT, PI : 8), (JD, LT, PI : 8), } \\
\text { (PTD, JD, LT, PU : 8) }\end{array}$ \\
\hline JJ & $\begin{array}{l}(\mathrm{PTD}, \mathrm{JJ}: \mathrm{8}),(\mathrm{PID}, \mathrm{JJ}: 8) \text {, (LR, JJ : 8), (PTD, PID, } \\
\mathrm{JJ}: 8) \text {, (PTD, LR, JJ : 8), (PD, LR, JJ : 8), (PTD, } \\
\text { PID, LR, JJ : 8) }\end{array}$ \\
\hline PTJ & $(\mathrm{PID}, \mathrm{PTJ}: \mathrm{8}),(\mathrm{JD}, \mathrm{PTJ}: 8),(\mathrm{PID}, \mathrm{JD}, \mathrm{PTJ}: 8)$ \\
\hline LT & $($ PTD, LT : 8), (JD, LT : 8), (PTD, JD, LT : 8) \\
\hline TR & 0 \\
\hline TS & $\begin{array}{l}\text { (PTD, TS : 8), (JD, TS : 8), (PID, TS : 8), (LR, TS } \\
: 8) \text {, (PID, LR, TS : 8) }\end{array}$ \\
\hline LR & (PTD, LR: 8), (PID, LR: 15), (PTD, PID, LR: 8) \\
\hline JD & $(\mathrm{PTD}, \mathrm{JD}: 8),(\mathrm{PID}, \mathrm{JD}: 8)$ \\
\hline $\mathrm{PID}$ & (PTD, PID : 8) \\
\hline PTD & 0 \\
\hline
\end{tabular}

Tabel 3.

Daftar association rule yang diperoleh

\begin{tabular}{|c|l|c|c|c|}
\hline No. & \multicolumn{1}{|c|}{ Rule } & Support & Conffdence & Lift \\
\hline 1 & PID => LR & $62,5 \%$ & $93,75 \%$ & 1.5 \\
\hline 2 & PTD => LR & $33,33 \%$ & $50 \%$ & 0.8 \\
\hline 3 & PTD dan PI => LR & $33,33 \%$ & $100 \%$ & 1.6 \\
\hline 4 & TS => LR & $33,33 \%$ & $66,67 \%$ & 1.0667 \\
\hline 5 & PID dan TS => LR & $33,33 \%$ & $100 \%$ & 1.6 \\
\hline 6 & JD $=>$ LT & $37,5 \%$ & $56,25 \%$ & 1.5 \\
\hline 7 & PTD => LT & $33,33 \%$ & $50 \%$ & 1.3333 \\
\hline 8 & PTD dan JD => LT & $33,33 \%$ & $100 \%$ & 2.6665 \\
\hline 9 & JJ => LR & $33,33 \%$ & $100 \%$ & 1.6 \\
\hline 10 & PTD dan JJ => LR & $33,33 \%$ & $100 \%$ & 1.6 \\
\hline 11 & $\begin{array}{l}\text { PTD dan PID dan JJ }=> \\
\text { LR }\end{array}$ & $33,33 \%$ & $100 \%$ & 1.6 \\
\hline 12 & PID dan JJ => LR & $33,33 \%$ & $100 \%$ & 1.6 \\
\hline 13 & PI $=>$ LT & $33,33 \%$ & $100 \%$ & 2.6665 \\
\hline 14 & PTD dan PI => LT & $33,33 \%$ & $100 \%$ & 2.6665 \\
\hline 15 & $\begin{array}{l}\text { PTD dan JD dan PI }=> \\
\text { LT }\end{array}$ & $33,33 \%$ & $100 \%$ & 2.6665 \\
\hline 16 & JD dan PI => LT & $33,33 \%$ & $100 \%$ & 2.6665 \\
\hline
\end{tabular}

med $=\frac{\min (x 1, x 2, x 3)+\max (x 1, x 2, x 3)}{2}$

dimana :

$\mathrm{x1}$ : jarak dengan rayon krian

$\mathrm{x} 2$ : jarak dengan rayon porong

x3 : jarak dengan rayon sidoarjo kota

Karena pembagian untuk masing-masing fitur geografi sama, maka diberlakukan cara yang sama. Untuk kategori dekat $(\leq$ med) dan jauh ( > med).

\section{A. Proses Asosiasi}

Pada bagian ini akan dijabarkan tentang alur berjalannya sistem. Seperti yang terlihat pada 1, sistem akan dimulai dengan mencari nilai support dari masing-masing item yang dilakukan dengan cara memindai data dari basis data. Nilai support ditentukan dari banyaknya kemunculan setiap item di keseluruhan record yang ada.

Setelah jumlah kemunculan atau nilai support dari masingmasing item didapatkan, selanjutnya akan dilakukan sorting atau pengurutan secara descending. Jadi item yang memiliki yang diperoleh dari GIS. 
nilai support tertinggi berada di urutan yang paling atas, begitu seterusnya sampai item yang memiliki nilai support terendah berada di urutan terbawah.

Selanjutnya setelah didapatkan urutan item berdasarkan nilai supportnya secara keseluruhan akan dilakukan pengurutan lagi, tetapi yang diurutkan kali ini adalah item-item yang ada di setiap record. Urutannya sesuai dengan urutan item yang diperoleh sebelumnya. Hal ini dikenakan pada setiap record yang tersedia.

Langkah selanjutnya adalah membentuk FP Tree. Caranya yaitu dengan mengubah masing-masing record menjadi sebuah path yang nantinya akan membentuk tree setelah semua path digabungkan.

Proses asosiasi bisa dilakukan setelah FP Tree sudah terbentuk. Untuk selanjutnya akan dilakukan ekstrak frequent pattern berdasarkan FP Tree tersebut. Ada beberapa langkah untuk mengekstrak frequent pattern dari Tree. Langkah yang pertama adalah mendapatkan conditional pattern base yang caranya dengan melihat pola-pola apa saja yang sudah terbentuk dengan memilih suatu item untuk dijadikan sebagai acuan. Item acuan tersebut dipilih mulai dari item yang menempati posisi terbawah atau anak terakhir. Begitu seterusnya sampai atribut yang mendekati root atau null.

Langkah kedua adalah membentuk conditional fp tree. Conditional fp tree (CFPT) ini dibentuk berdasarkan CPB yang diperoleh sebelumnya, bukan berdasarkan basis data awal lagi.

Langkah berikutnya kita bisa mendapatkan frequent pattern yang sesuai dengan CFPT tersebut. Baru setelah memeperoleh frequent pattern kita bisa menemukan rule yang mungkin terbentuk dengan cara mengkombinasikan seluruh item-item yang terdapat di masing-masing frequent pattern tersebut menjadi bentuk $\mathrm{A} \Rightarrow \mathrm{B}$ dengan $\mathrm{A}$ dan $\mathrm{B}$ terdiri dari satu atau lebih item dan item yang termasuk di A tidak termasuk di B atau dengan kata lain A dan B tidak memiliki irisan.

\section{HASIL PENELITIAN}

Seperti pada Gambar 2 dengan transparency yang sesuai kita bis a membuat poligon untuk membatasi daerah Sidoarjo. Lalu membagi daerah Sidoarjo menjadi 3 bagian dengan menggunakan line sesuai dengan pembagian wilayah rayon dari PLN.

Fitur-fitur geografi yang dibutuhkan juga ikut dibuat sehingga nantinya akan terbentuk beberapa layer. Setelah itu menentukan titik pusat dari masing-masing rayon dan fitur geografi tersebut. Penentuan jarak diukur dari titik pus at rayon ke titik pusat fitur geografi seperti pada Gambar 3.

Setelah jarak masing-masing rayon dengan masing-masing fitur geografi didapatkan, maka seperti yang sudah dijelaskan sebelumnya akan dihitung mediannya. Nilai kurang dari atau sama dengan median dikategorikan dekat dan lebih dari median dikategorikan jauh.

Dalam sub bab ini dijelaskan salah satu hasil dari penelitian yang sudah dilakukan dan mewakili semua percobaan. Dengan menggunakan data 8 bulan dan minimal support $30 \%(7,2)$.

Setelah menghitung nilai support masing-masing item dan diurutkan lalu item yang ada di setiap record juga harus diurutkan sesuai urutan per item sebelumnya. Sehingga fp tree bisa dibentuk dari gabungan semua path yang mana setiap path mewakili satu record.

Untuk selanjutnya akan dilakukan ekstrak frequent pattern berdasarkan $f p$ tree tersebut. Ada beberapa langkah untuk mengekstrak frequent pattern dari tree. Langkah yang pertama adalah mendapatkan conditional pattern base yang caranya dengan melihat pola-pola apa saja yang sudah terbentuk dengan memilih suatu item untuk dijadikan sebagai acuan. Item acuan tersebut dipilih mulai dari item yang menempati posisi terbawah atau anak terakhir. Begitu seterusnya sampai item yang mendekati akar atau null (Gambar 4).

Setelah itu hitung jumlah kemunculan setiap item yang ada pada conditional pattern base masing-masing item acuan. Dan item yang memiliki support dibawah nilai support akan dihilangkan. Sehingga kita bis a mendapatkan frequent pattern nya. (Tabel 2)

Merujuk pada tujuan penelitian ini yaitu untuk mengetahui pola hubungan antara penggunaan listrik dengan temperatur dan fitur geografi, maka FPG yang akan diamati dan dianalis is yaitu FPG yang mempunyai atribut LR atau LT.

Setelah menemukan frequent pattern pada Tabel 2, selanjutnya akan digenerate rule-rule yang bisa dibentuk berdasarkan frequent pattern tersebut (Tabel 3).

\section{ANALISA DAN KESIMPULAN}

Maka dari percobaan di atas didapat 5 association rule yang berhubungan dengan fitur geografi dan selalu mempunyai nilai lift ratio tertinggi, serta 2 association rule yang berhubungan dengan temperatur, yaitu:

1. Jika jarak dengan pertanian dan jalan besar dekat maka konsumsi listrik tinggi.

2. Jika jarak dengan perikanan jauh maka konsumsi listrik tinggi.

3. Jika jarak dengan prtanian dekat dan dengan perikanan jauh maka konsumsi listrik tinggi.

4. Jika jarak dengan pertanian dan jalan besar dekat dan dengan perikanan jauh maka konsumsi listrik tinggi.

5. Jika jarak dengan jalan besar dekat dan dengan perikanan jauh maka konsumsi listrik tinggi.

6. Jika temperatur sedang maka konsumsi lis trik rendah.

7. Jika jarak dengan perikanan dekat dan temperatur sedang maka konsumsi lis trik rendah.

Dari rule yang terbentuk terdapat 3 macam pengertian. Dilihat dari nilai lift rationya, jika nilainya $<1$ maka rule tersebut berkorelasi negatif atau dengan kata lain kemunculan salah satu item A atau B mempengaruhi hal yang sebaliknya pada kemunculan item lainnya. Jika nilai liftnya $=1$ maka A dan B tidak ada korelasi atau bisa dikatakan independent. Dan jika bernilai > 1 maka rule ini dikatakan berkorelasi positif yang berarti kemunculan salah satu A atau B berhubungan dengan kemunculan yang lainnya.

\section{DAFTAR PUSTAKA}


electricity consumption," Energy, vol. 88, pp. 604-609, 2015.

[2] A. Kipping and E. Tromborg, "Hourly electricity consumption in Norwegian households-Assessing the impacts of differentheating systems," Energy, vol. 93, pp. 655-671, 2015.

[3] M. . Wijaya and T. Tezuka, "A comparative study of households' electricity consumption characteristics in Indonesia: A techno-socioeconomic analysis," Energy Sustain.
Dev., vol. 17, pp. 596-604, 2013.

[4] R. . Rathod and R. . Garg, "Regional electricity consumption analysis for consumers using data mining techniques and consumer reading data," Electr. Power Energy Syst., vol. 78, pp. 368-374, 2016.

[5] Kusrini and E. . Luthfi, Algoritma Data Mining. Yogyakarta: Andi, 2009. 